\title{
The state of theory in three premier advertising journals: a research note
}

\author{
Leyland F. Pitt \\ Simon Fraser University \\ Pierre Berthon \\ Bentley College \\ Albert Caruana \\ University of Malta \\ Jean-Paul Berthon \\ Richmond, The American University in London
}

\begin{abstract}
Despite its importance, little is known about the prevalence of theory in the literature on advertising research. Utilising a content analysis of the three premier advertising journals over an 11-year period, it is found that only $17 \%$ of articles have made explicit use of theory. Psychology is the discipline from which the greatest number of articles drew their theoretical frameworks, followed by sociology and economics - indeed, theories from marketing and advertising are in the minority. Limitations are noted and implications of the results are discussed.
\end{abstract}

\section{Introduction}

Theory informs practice and practice informs theory; advertising journals play a key role in this cycle, as they act as a vital conduit through which research findings are disseminated. Despite their potential usefulness, theories are always provisional (cf. Popper 1968), with each additional piece of theory-based research acting as a further test. The noted physicist Steven Hawking (2002) likened the creation and testing of theory to a boat - the builder constructs a craft believing that it will float and sail, and then tests it by launching it onto the water. In the social sciences, a theory attempts to explain a particular social or behavioural phenomenon: if it

International Journal of Advertising, 24(2), pp. 241-249

(C) 2005 Advertising Association

Published by the World Advertising Research Center, www.warc.com 
succeeds, the theory 'floats'; if it doesn't and reality turns out to be different from what was theorised, the theory 'sinks', and the researcher will look for alternative explanations. However, even when the boat floats, further testing is needed - there are many different types of water and weather, and different designs of boat are needed under different conditions.

Given the importance of theory, it is perhaps surprising that there have been few specific attempts to study the role of theory in advertising research. The importance of conceptual work in marketing in general, and in consumer behaviour in particular is highlighted by MacInnis (2004) in a recent newsletter in which she decries the paucity of conceptual work or theory building in marketing. We seek to answer two questions. First, to what extent is advertising research specifically grounded in theory? Second, which disciplines do theories used in advertising come from? After briefly considering the role of theory in research, this paper describes the process and results of a content analysis of three major journals in advertising over an 11-year period that provide some answers to these questions.

\section{Theory and research in advertising and marketing}

Hunt (1991) defines a theory as a systematically related set of statements, including some law-like generalisations, which are empirically testable. A theory should give direction to the research effort needed to solve a specific problem or shed light on a situation. Theory forces research on specific areas, as well as providing alternative views and solutions to problems. Marketing academics have attempted to develop both unique, standalone marketing theories as well as applying theories from other disciplines to marketing problems. In the case of the former, scholars have formulated 'general theories' of marketing, involving philosophies that endeavour to explain a broad range of marketing phenomena and problems (e.g. Alderson 1957, 1958; Alderson \& Martin 1967; Bagozzi 1975). In the case of the latter, academics have concentrated on the development of theories that are more specific in their domain, and seek to account for narrower marketing problems and phenomena, such as relationship marketing (e.g. Morgan \& Hunt 1994), the dynamics of competitive markets (Dickson 1992), or a critical theory of multicultural marketing (Burton 
2002). However, rather than formulate new marketing theories, many marketing researchers have concentrated their efforts on applying theories developed in other disciplines to specific marketing problems. For example, transaction cost theory from economics and cognitive dissonance theory in psychology have provided the framework for a variety of research undertakings in marketing. To guide our investigation we offer two broad propositions to address the main research questions outlined in the introduction, 'To what extent is advertising research specifically grounded in theory?' and 'Which disciplines do theories used in advertising come from?'

Armstrong (1979) identifies two approaches to research in marketing. First, exploratory or inductive research, which comprises essentially a theoretical exploration, where no formal hypothesis about a phenomenon is proposed (typically due to the novelty of the topic). Second, hypothesisdriven or deductive research, where a single theory or multiple competing theories are used to develop hypotheses about a particular phenomenon. Armstrong et al.'s (2001) audit of six top marketing journals revealed that the majority of articles were theoretically deductive and hypothesis-driven whereas the minority were purely exploratory or inductive. Given the close relationship between marketing and advertising, this leads us to our first proposition:

P1: A majority of articles in premier advertising journals will be theory-driven.

At the same time a number of authors (e.g. Leone \& Schultz 1980; Anderson 1994; Armstrong et al. 2001; Armstrong 2002) have observed that marketing research has produced few theoretical generalisations, inferring that theory development in marketing has not developed at the same rate as in other disciplines (Bloom 1987; Bass 1993). This leads us to our second proposition:

P2: Of the theory-driven articles in premier advertising journals, the majority will rely on theory developed in disciplines outside advertising and marketing. 
There is general consensus that both the development and application of strong theory are important in marketing research in general and advertising research in particular. However, to date no research has explicitly looked at the extent and nature of theory use in advertising research. In the next section we describe a content analysis of premier advertising journals designed to address these issues. Three advertising journals namely Journal of Advertising (JA), Journal of Advertising Research (JAR) and International Journal of Advertising (IJA) - are recognised as the premier journals in the specialised area of advertising (Hult et al. 1997; Theoharakis \& Hirst 2002). Based on studies conducted on marketing journals we propose that a majority of articles in premier advertising journals will be theory-driven, and of the theory-driven articles the majority will rely on theory developed in disciplines outside advertising and marketing.

\section{Methodology}

A content analysis was conducted on the three specialised advertising journals over a period of 11 years, from January 1991 to December 2001. Out of a total article base of 1122, the non-inclusion of 122 papers, which consisted of comments, book reviews or replies to other articles, left a total of 1000 articles that were analysed in this study. Two researchers each conducted their own literature reviews and compared conclusions, with exceptions or disagreements being resolved by a third researcher. Each reviewer sought to identify the use or otherwise of theory in each of the articles in the journals. As it is difficult to establish the exact parameters of what may be considered 'theory-driven', the study and the literature reviews were limited to those that specifically mentioned a theory in the contents of the article. For example, a typical paper that was considered theory-driven may have read: 'social comparison theory can be used to describe the behaviour that is expressed in teens in relation to how they relate to peers in buying behaviour'. Social comparison theory is what is referred to as an explicit theory in this case. The data collected consisted of the characteristics of each article in terms of: the journal it came from; the year of publication; whether an explicit mention of a theory was made; which theory this was; and its discipline of origin (e.g. psychology, sociology). 


\section{Results}

Table 1 provides a summary of data collected by journal and the number of articles that make an explicit reference to theory. JAR papers are more numerous because the journal is published bi-monthly, while JA and IJA are quarterly publications. Results show that, overall, only $17 \%$ of articles made explicit mention of theory, with JA showing the highest percentage at $29.2 \%$, more than double that of IJA and JAR. To the extent that an explicit reference to theory is an indication that an article is theory-driven, these results do not provide support for $\mathrm{P} 1$, which held that a majority of articles in premier advertising journals will be theory-driven.

Figure 1 provides a time series over 11 years of the percentage of papers that make explicit mention of theory in each journal. For all three journals the years 1993 and 1995 appear to have shown a drop, while 1999 witnessed a peak. Encouragingly at least, theory use in advertising has not matched the decline in conceptual work bemoaned by MacInnis (2004) in the field of consumer behaviour, although it should be remembered that we consider theory use while MacInnis considers theory development. Indeed, were the latter to be considered in advertising it is likely that the same situation would be encountered. Over the period under consideration JA and IJA exhibit a positive trend in the number of papers that make an explicit mention of theory, while JAR, which is more practitionerorientated, is more even. This would seem to suggest that the use of theory in advertising research among the more academic journals has shown some strengthening over the years.

Figure 2 shows the discipline of origin of theory-driven papers appearing in the respective journal over the 11 years considered. Results show

Table 1: Details of articles reviewed and those making explicit mention of theory

\begin{tabular}{lrrrr}
\hline & JA & IJA & JAR & Total \\
\hline Total article base considered & 295 & 308 & 519 & 1122 \\
Minus articles not included & 21 & 44 & 57 & 122 \\
Total number of articles analysed & 274 & 264 & 462 & 1000 \\
Number of articles with explicit mention of theory & 80 & 32 & 58 & 170 \\
\% of articles with 'explicit theory' & 29.2 & 12.1 & 12.6 & 17.0 \\
\hline
\end{tabular}




\section{Figure 1: Time series of the percentage of papers that make an explicit mention of theory in each journal}

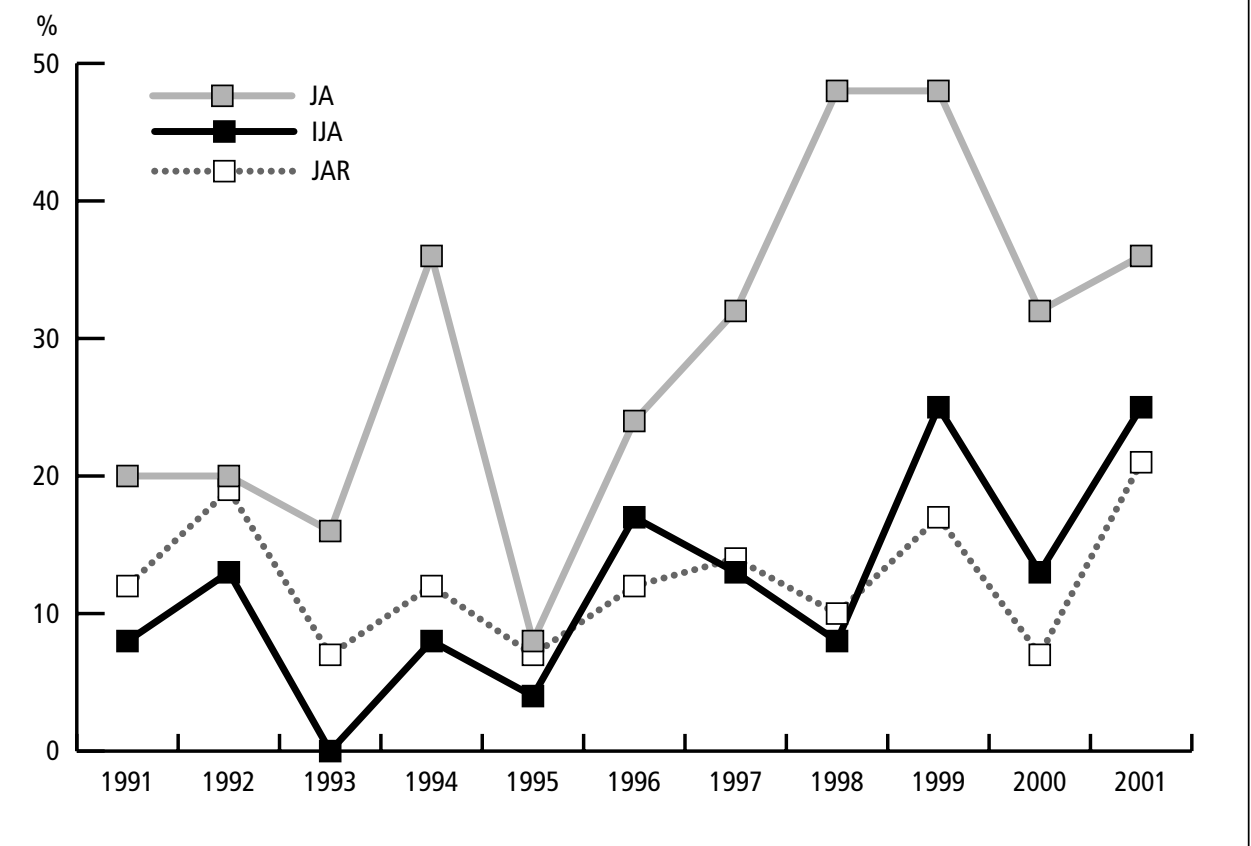

that psychology, sociology and economics, rather than advertising and marketing, are providing the theories that are being used in the three journals. While IJA published the narrowest spread in terms of theories cited, as compared to JA and JAR, the range of theories cited in JAR (which tends to publish empirical research) seems to be a little wider than in the other two journals and includes papers applying theories from relatively unrelated disciplines such as biology and law. It will also be observed from Figure 2 that there were only five papers based in advertising theory and two in marketing theory. These results provide support for $\mathrm{P} 2$, which held that, of the theory-driven articles in premier advertising journals, the majority will rely on theory developed in disciplines outside advertising and marketing.

Table 2 shows the most frequently used theories in the three journals over the period studied. Theories from advertising and marketing did not feature at all among the ten dominant theories appearing in these journals. Interestingly, persuasion theory figures predominantly in IJA, while JA made particular reference to social comparison theory, socialisation theory, 
Figure 2: Discipline of origin of theory-driven papers as a percentage of all papers

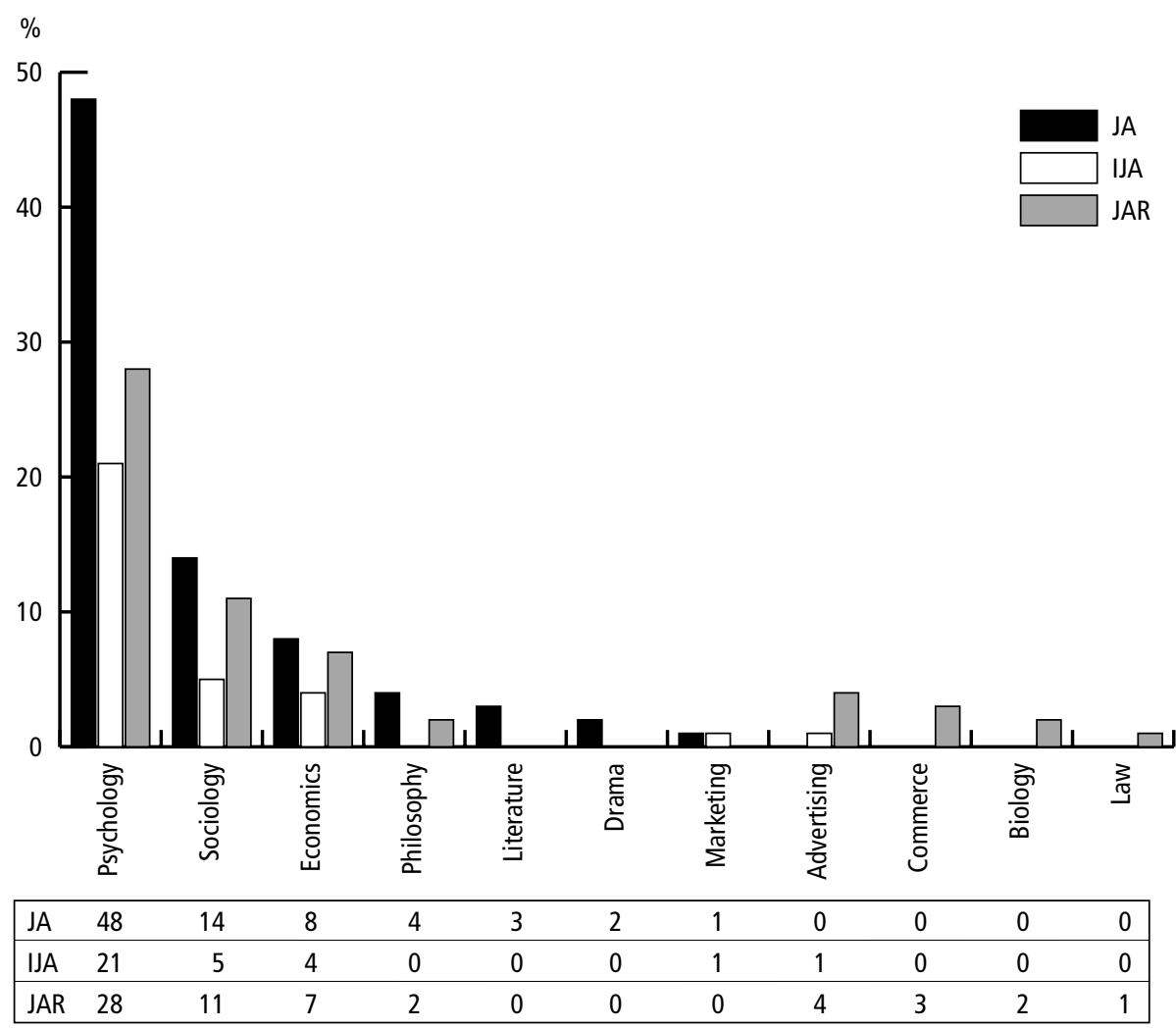

\section{Table 2: The ten most frequently used theories}

\begin{tabular}{lllll}
\hline & JA & IJA & JAR & Total \\
\hline 1. Persuasion theory & 0 & 6 & 0 & 6 \\
2. Social comparison theory & 4 & 0 & 1 & 5 \\
3. Socialisation theory & 4 & 0 & 1 & 5 \\
4. Emotion theory & 3 & 0 & 1 & 4 \\
5. Classical conditioning theory & 3 & 0 & 2 & 4 \\
6. Information processing theory & 2 & 0 & 0 & 4 \\
7. Learning theory & 1 & 3 & 1 & 4 \\
8. Means end chain theory & 0 & 3 & 1 & 4 \\
9. Prospect theory & 2 & 1 & 1 & 3 \\
10. Agency theory & 1 & 1 & & 4 \\
\hline
\end{tabular}


emotion theory and classical conditioning theory to explain advertising and marketing phenomena. On the other hand, reference to explicit theories was fairly evenly distributed in JAR.

\section{Discussion}

This paper has considered the role of theory in the advertising literature over an 11-year period, utilising a content analysis of the three major advertising journals. Results show that only a minority of articles made explicit use of theory and the majority of theories used in advertising research come from disciplines outside advertising and marketing. In more detail, it was found that explicit theories feature with greater prevalence in articles published in JA, although the trend seems to be towards a greater reliance on theory in all three journals. Psychology is the discipline from which the greatest number of articles drew their theoretical frameworks, followed by sociology and economics. Theories from marketing and advertising are in a minority.

Any generalisations should bear two points in mind. First, we have used a mention of theory in the text of a paper as a surrogate for that paper being theory-driven. Second, the results pertain only to the three premier advertising journals considered. Other advertising journals are likely to be weaker in terms of usage of theory. However, there seems to be a growing recognition of the importance of theory in research in the major advertising journals. If this trend continues then there is no doubt that authors will increase their chances of publication by grounding their research more strongly in theory. This is particularly true when deciding which journal to target for publication - at the moment, for example, it would seem that the research published in JA is based on theory to a considerably greater extent. Perhaps the greatest publication opportunities for advertising and marketing scholars (as well as the prospects of making a lasting contribution to their disciplines) lie in their willingness to develop the new theories that will change the way we think about our subject areas.

\section{Acknowledgements}

The authors acknowledge the help and assistance of Aileen Chow Chwee Yong, Marketing Consultant, Southeast Asia in gathering some of the data. 


\section{References}

Alderson, W. (1957) Marketing Behavior and Executive Action. Homewood, IL: Richard D. Irwin.

Alderson, W. (1958) The analytical framework for marketing. Proceedings - Conference of Marketing Teachers from Far Western States. Berkeley, CA: University of California Press.

Alderson, W. \& Martin, M.W. (1967) Toward a formal theory of transactions and transvections, in Mallen, B.E. (ed.) The Marketing Channel: A Conceptual Viewpoint. New York, NY: John Wiley \& Sons.

Anderson, L.M. (1994) Marketing science: where's the beef? Business Horizons (Jan-Feb), pp. 8-16.

Armstrong, J.S. (1979) Advocacy and objectivity in science. Management Science, 25, pp. $423-428$.

Armstrong, J.S. (2002) Discovery and communication of important marketing findings: evidence and proposals. Journal of Business Research, 56, pp. 69-84.

Armstrong, J.S., Brodie, R.J. \& Parsons, A.G. (2001) Hypotheses in marketing science: literature review and publication audit. Marketing Letters, 12(2), pp. 171-187.

Bagozzi, R.P. (1975) Marketing as exchange. Journal of Marketing, 39, October, pp. 32-39.

Bass, F.M. (1993) The future of research in marketing: marketing science. Journal of Marketing Research, 30, pp. 1-6.

Bloom, P.N. (1987) Knowledge Development in Marketing. Lexington, MA: Lexington Books.

Burton, D. (2002) Towards a critical multicultural marketing theory. Marketing Theory, 2(2), pp. 207-236.

Dickson, P.R. (1992) Toward a general theory of competitive rationality. Journal of Marketing, 56, January, pp. 69-83.

Hawking, S. (2002) The Theory of Everything: The Origin and Fate of the Universe. Princeton: New Millennium.

Hult, G.T.M., Neese, W. \& Bashaw, R.E. (1997) Faculty perceptions of marketing journals. Journal of Marketing Education, 19(1), pp. 37-52.

Hunt, S.D. (1991) Modern Marketing Theory: Critical Issues in the Philosophy of Marketing Science. Cincinnati, OH: South-Western Publishing Company.

Leone, R.P. \& Schultz, R. (1980) A study of marketing generalizations. Journal of Marketing, 44, pp. 10-18.

MacInnis, D. (2004) Where have all the papers gone? ACR News, Spring, pp. 1-3.

Morgan, R.M. \& Hunt, S.D. (1994) The commitment-trust theory of relationship marketing. Journal of Marketing, 58(3), pp. 20-39.

Popper, K. (1968) The Logic of Scientific Discovery. New York: Harper \& Row.

Theoharakis, V. \& Hirst, A. (2002) Perceptual differences of marketing journals: a worldwide perspective. Marketing Letters, 13(4), pp. 389-402. 
Copyright of International Journal of Advertising is the property of WARC World Advertising Research Center and its content may not be copied or emailed to multiple sites or posted to a listserv without the copyright holder's express written permission. However, users may print, download, or email articles for individual use. 